2020-12-31

Fatigue crack growth and fatigue

fracture morphology of recycled rubber powder filled NR/BR blend compound

Abang Ismawi Hassim, DH

http://hdl.handle.net/10026.1/15347

10.5254/rct.20.80440

Rubber Chemistry and Technology

American Chemical Society

All content in PEARL is protected by copyright law. Author manuscripts are made available in accordance with publisher policies. Please cite only the published version using the details provided on the item record or document. In the absence of an open licence (e.g. Creative Commons), permissions for further reuse of content should be sought from the publisher or author. 


\title{
FATIGUE CRACK GROWTH AND FATIGUE FRACTURE MORPHOLOGY OF RECYCLED RUBBER POWDER-FILLED NR/BR BLEND COMPOUND
}

\author{
D. H. ABANG ISMAwi HASSIM, ${ }^{1,2}$ FranK ABRAHAM, ${ }^{2, *}$ JOHN SUMmERSCALES $^{2}$ \\ ${ }^{1}$ Malaysian Rubber BoARd, RRIM EXPERIMENT STATION, 47000, SG. BUlOH, SElangOr, MALAYSIA \\ ${ }^{2}$ SCHOOL OF ENGINEERING, COMPUTING AND MATHEMATICS, UNIVERSITY OF PLYMOUTH, PLyMOUTH PL4 8AA, UNITED
}

KINGDOM

RUBBER CHEMISTRY AND TECHNOLOGY, Vol. 00, No. 0, pp. 000-000 (0000)

\begin{abstract}
The effect of two different types and particle sizes (micronized cryo-ground $74 \mu \mathrm{m}$ or ambient-ground $400 \mu \mathrm{m}$ ) of recycled rubber powder (RRP) was studied during fatigue crack growth (FCG) in an NR/BR compound using a fracture mechanics approach. Absolute and relative hysteresis losses using single-edge notch tensile specimens were determined with a displacement-controlled strain compensating for the permanent set of the samples throughout the FCG experiments. Differences in relative hysteresis loss showed that additional energy dissipation, due to multiple new crack surfaces at the crack tip, contributes to the FCG of the RRP compounds. At higher tearing energy, beside other factors affecting the FCG performance of the RRP compounds, both higher absolute and relative hysteresis loss are slightly detrimental to the crack growth rates. At lower tearing energy, the larger RRP-filled compound showed slower, but not significant, different crack growth rates than the NR/BR control compound. Fracture morphologies for NR/BR and RRP-filled compound were associated with different fracture surface topographies at various tearing energies, which revealed the dependency of the crack growth microstructure on the tearing energies. [doi:10.5254/rct.20.80440]
\end{abstract}

\section{INTRODUCTION}

Quasi-static properties such as tensile strength, abrasion, and tear resistance give simple and quick information, which is often used for quality control of rubber compound. However, these tests do not describe the rubber performance in dynamic conditions. Wear loss in tires or cracking in rubber mountings is usually associated with crack growth due to repeated cyclic stress. These types of failure under cyclic/repeated conditions are known as fatigue failure and occur well below the ultimate strength of the material. ${ }^{1}$ Suitable parameters for assessing material properties and their relation to lifetime performance in specific applications are required. The most practical approach is fracture mechanics, in which the crack growth rate is influenced by the tearing energy of the rubber material and is independent of the shape of the test piece. The energy balance theory was first used in rubber tearing under static loading by Rivlin and Thomas, ${ }^{2}$ who derived their model from Griffith's criterion. ${ }^{3}$ The tearing energy, also well known as the "energy release rate," can be applied for cyclic loading ${ }^{1}$ and is widely used as a criterion for fatigue crack growth (FCG) rate in elastomers.

In many studies of recycled rubber materials, using untreated or treated powder, only quasistatic mechanical properties are reported. ${ }^{4-7}$ Generally, few works have examined the fatigue properties and fracture morphology. In a fatigue life evaluation, both $\operatorname{Han}$ and $\operatorname{Han}^{8}$ and Bandyopadhyay et al. ${ }^{9}$ used DeMattia flex cracking (DMFC) for crack growth rate measurements. Roche and Perier ${ }^{10}$ evaluated the effect of filler dispersion and rubber formulation on the FCG behavior of styrene-butadiene rubber (SBR). Those authors reported that fracture mechanics based on the energetic approach provides more precise information than the conventional standard fatigue methods (DMFC) or fatigue-to-failure tests (FTFT). Other authors ${ }^{11-13}$ highlighted the contradictory performance of rubber compounds at different tearing energies. This energetic approach to crack growth analysis could provide new information for recycled rubber powder-

*Corresponding author. Email: frank.abraham@plymouth.ac.uk 
TABLE I

RUBBER FORMULATIONS (IN PPHR)

\begin{tabular}{lcc}
\hline Master batch & & \\
\hline NR/BR & 100 & 100 \\
Zinc oxide & 3.5 & 3.5 \\
Stearic acid & 2.5 & 2.5 \\
Antilux 654 wax & 1 & 1 \\
6PPD antioxonant & 2.5 & 2.5 \\
Flectol TMQ antioxidant & 1 & 1 \\
N234, carbon black & 30 & 30 \\
MRP074/CRP400 & 0 & 10 \\
\hline
\end{tabular}

6PPD: N-1,3-dimethylbutyl-N' phenyl-p-phenylenediamine

TMQ: 2,2,4-trimethyl-1,2-dihydroquinoline

filled compound evaluation. Recently, Yaagoubi et al. ${ }^{14}$ showed that crack growth behavior together with the J-integral concept of Rice ${ }^{15}$ allow for reasonable predictions of FCG, even for complex-shaped test specimens.

The fatigue fracture surface morphology and the mechanism of FCG for NR compounds have been comprehensively studied. ${ }^{16-19}$ Tee et al. ${ }^{20}$ showed that from year 2004 until present, $49 \%$ of studies on rubber fatigue focused on NR, $21 \%$ on SBR, $25 \%$ on other rubber types, and only $5 \%$ on rubber blend. In the present work, the FCG in NR/BR blend (70/30 compound) with cryogenicground micronized rubber powder (at $<74 \mu \mathrm{m}$, denoted MRP074) is compared with ambientground crumb rubber powder (at $<400 \mu \mathrm{m}$, denoted CRP400) using a fracture mechanics approach. Recycled rubber powder (RRP) refers to either MRP074 or CRP400 filler. The effect of both RRP at $10 \mathrm{pphr}$ (parts per hundred of rubber) on the damage to the microstructure of NR/BR (70/30) and fatigue fracture surface morphology dependence on the FCG under different strain amplitudes are also studied. The FCG performance of RRP-filled NR/BR compound at different strain amplitudes is important, as materials behave differently under different tearing energies. ${ }^{12}$

\section{EXPERIMENTAL}

\section{MATERIALS}

The rubber matrix was an NR/BR blend system (70/30 ratio). The blend ratio of 70/30 was selected ${ }^{21}$ to balance properties such as abrasion, strength, fatigue, and crack growth resistance for tire tread formulation. Driven by their targeted properties, other authors have used NR/BR ratios of $50 / 50^{22,23}$ or $60 / 40 .^{24}$ The NR was standard Malaysian rubber 10 . BR was cis-1,4 polybutadiene rubber (Europrene Neo cis-BR-40). The CRP400 and MRP074 recycled materials were from different batches of truck tires. Crumb rubber powder (CRP400) at 40 mesh $(\sim 400 \mu \mathrm{m})$ particle size was supplied by Crumb Rubber Ltd. (Plymouth, UK). Micronized rubber powder (MRP-Polydyne 200) at 200 mesh $(74 \mu \mathrm{m})$ was supplied by Lehigh Technologies (Tucker, GA, USA). The characterization of those materials is published elsewhere. ${ }^{25}$ Other chemical ingredients used were of commercial grade (Table I). The curatives, $1.2 \mathrm{pphr}$ sulfur and $1 \mathrm{pphr}$ N-tert-butyl-2benzothiazole sulfenamide, were added during final mixing. All rubber and chemical ingredients were supplied by Tun Abdul Razak Research Centre (Brickendonbury, UK). 


\section{MIXING PROCESS AND COMPOUND PREPARATION}

NR was masticated to reduce the viscosity to a nominal 60 Mooney units $\left(\mathrm{ML}[1+4]\right.$ at $\left.100{ }^{\circ} \mathrm{C}\right)$ using a Bridge cracker mill ( $406 \mathrm{~mm} \emptyset \times 508 \mathrm{~mm}$ length) and then a two-roll mill (Francis Shaw, 50 $\mathrm{kg}$ capacity). Three master batches of NR/BR compound were prepared using a Polylab $2000 \mathrm{E}$ internal mixer $\left(390 \mathrm{~cm}^{3}\right.$ and fill factor of 0.72$)$. The raw NR and BR were mixed simultaneously before addition of carbon black (CB), RRP, and other compounding ingredients. The master batch mixing was carried out with a starting temperature of $40{ }^{\circ} \mathrm{C}$ and a rotor speed of $60 \mathrm{rpm}$. Total mixing time was about $6.5 \mathrm{~min}$. The master batches were allowed to cool overnight before the curatives were added separately using a two-roll mill. A band of rubber was formed as a continuous sheet on the mill. Once the curatives had all been added, the banded rubber was cut and rolled three times from each side of the mill, alternating from the left and from the right. After that, the entire compound was removed as a roll and passed through a tight nip for three passes, not allowing the rubber to band but taking off as a roll. The number of cuts and passes is kept low to minimize degradation of the rubber matrix while ensuring good dispersion of the curatives. Each mix was then sheeted out at approximately $4-5 \mathrm{~mm}$ thickness.

The optimum curing times, $\mathrm{t}_{95}$ (time at $95 \%$ of the maximum torque rise), of all samples were obtained at $160^{\circ} \mathrm{C}$ for $30 \mathrm{~min}$, using a Monsanto MDR 2000 rheometer with $0.5^{\circ}$ arc in accordance with the BS ISO 6502:2016 standard. Compression molding of test specimens from each mix used a Bradley and Turton Ltd. (Kidderminster, UK) steam press at $160{ }^{\circ} \mathrm{C}$ with $8 \mathrm{MPa}$ pressure. The 229 $\mathrm{mm}$ square by $2 \mathrm{~mm}$ thick sheets were molded using their respective optimum cure times.

\section{FCG TEST}

FCG tests were conducted on an Instron Electropuls 3000 with a $250 \mathrm{~N}$ load cell, at ambient conditions, using displacement control mode with a superimposed minimum load control. FCG tests were carried out on NR/BR CB-filled compound (control) and with $10 \mathrm{pphr}$ of either MRP074 or CRP400 filler. Single-edge notched tensile (SENT) dumbbell-shaped specimens had a rectangular cross section of $15 \times 2 \mathrm{~mm}$ with $40 \mathrm{~mm}$ distance between grips from the total specimen length of $100 \mathrm{~mm}$. Several authors used a precrack size of $1 \mathrm{~mm} .^{26,27}$ This precrack size is not appropriate for this study because at this length, the critical size has already been exceeded and there is no stable crack propagation, especially at higher dynamic strains. An initial crack of approximately $0.65 \pm 0.15 \mathrm{~mm}$ was cut into the narrow edge of each rubber specimen using a sharp razor blade. The specimens were quasi-statically stretched to $18 \mathrm{~mm}(\sim 107 \%$ strain $)$ maximum displacement to introduce a natural crack shape prior to dynamic testing. Three specimens per amplitude were then individually subjected to a sinusoidal excitation at a frequency of $5 \mathrm{~Hz}$ and 6,9 , 11 , or $15 \mathrm{~mm}$ strain amplitude, which corresponds, respectively, to $40 \%, 59 \%, 71 \%$, or $96 \%$ dynamic strain. Because of cyclic stress relaxation, and to avoid buckling of the rubber material, the targeted minimum load was fixed to $1 \mathrm{~N}(\sim 0.04 \mathrm{MPa})$ with constant peak displacement using trimodal control of the Instron WaveMatrix ${ }^{\mathrm{TM}}$ test software. The specimens were illuminated from both the front and the back with light-emitting diodes to achieve a greater image contrast. The tests were periodically stopped at a specific number of cycles, and the image of the crack was captured by a camera (computar ${ }^{\circledR}$, MLH-10X). The posttreatment measurement of the crack length was conducted using ImageJ software ${ }^{28}$ with semiautomatic ABSnake plugins. ${ }^{29}$ The half-crack contour lengths were measured at a specific number of cycles. For the first 5000 cycles at lower, or 3000 cycles at higher, dynamic strain, respectively, the measurements were not used for the $d c / d n$ because of the unstable crack growth at the beginning of the FCG test. In this condition, after 5000 cycles of FCG, the value of the precrack size does not matter. The crack growth rate $(d c / d n)$ from the 
stable crack growth region was obtained within the linear slope of the crack length $(c)$ plotted against the number of elapsed fatigue cycles.

Fracture behavior is characterized by a relationship between crack growth rate, $d c / d n$, and tearing energy, $T$, which is recognized as a fundamental property of crack propagation in elastomers. ${ }^{30}$ The tearing energy or strain energy release rate for SENT specimens under cyclic loading can be calculated using Eqs. 1 and 2:

$$
\begin{aligned}
T & =2 k W c \\
k & =\frac{\pi}{\sqrt{\lambda}}
\end{aligned}
$$

where $W$ is the strain energy density or stored energy at some distance from the crack (i.e., the integral area under the retraction load-displacement curves was divided by the volume of the specimen between the grips), $c$ is the crack length, $\lambda$ is the extension ratio (i.e., $\lambda=1+$ strain), and $k$ is a constant, depending on the strain (Eq. 2). Energy at the minimum strain level ( $\left.W_{\text {min }}\right)$ was taken into account for $W$ because the test was conducted under nonrelaxing conditions (minimum load $>$ $0)$. $W$ was measured using an unnotched specimen, which was cycled under the same conditions as in the FCG test for each of the strain amplitudes tested. Using the power-law relation $(d c / d n=$ $\left.B(T)^{F}\right)^{1}$, (Eqs. 1 and 2), the cyclic crack growth rate with tearing energy, $T$, can be expressed as

$$
d c / d n=B\left(2 \pi^{-1 / 2} W c\right)^{F}
$$

where $B$ and $F$ are material specific constants.

\section{HYSTERESIS LOSS}

The hysteresis loss/energy dissipated is defined as the difference between total work done for cyclic loading $\left(U_{a}\right)$ and cyclic unloading/retraction $\left(U_{s}\right)$ obtained from the integral area under the cyclic force displacement curve. Total energy density, $W_{a}$, and strain energy density, $W_{s}$, were determined by dividing the $U_{a}$ and $U_{s}$ by the volume of the specimen between specimen grips during cyclic loading. As the test was conducted under nonrelaxing conditions (minimum load $>$ 0 ), the energy at the minimum strain level $\left(U_{\mathrm{min}}\right)$ is included in both the total and strain energy. Measurement of the hysteresis loss from the energy densities (total and strain energy) was then acquired using the same SENT specimen during the FCG test. All of the energy measurements were obtained from a representative stress-strain hysteresis loop at the number of fatigue cycles closest to $50 \%$ of the service life for each specimen. The value of $50 \%$ was chosen as it best describes the average mechanical properties (mechanical properties change with each and every cycle) during the entire lifetime of the specimen. ${ }^{31}$ The percentage of relative hysteresis $\left.H_{r}[\%]=\left(W_{a}-W_{s}\right) / W_{a}\right) \times$ 100 and absolute hysteresis density $H_{a b}=\left(W_{a}-W_{s}\right)$ were then determined using an average of the three measurements. The averages and the standard deviations of the total and strain energy density and hysteresis loss as the absolute value and percentage of relative hysteresis of the total energy for the three rubber compounds for each level of strain amplitudes tested were reported.

\section{MORPHOLOGY OF FRACTURE SURFACES FROM THE FCG TEST}

Fracture surface specimens were cut about $5 \mathrm{~mm}$ from the fracture surface, and all specimens were gold coated to minimize electrical charging prior to analysis. The morphology of each crack fracture surface after FCG test was viewed using a JEOL JSM-6610 LV scanning electron microscope (SEM), operating at $15 \mathrm{kV}$ accelerating voltage. 


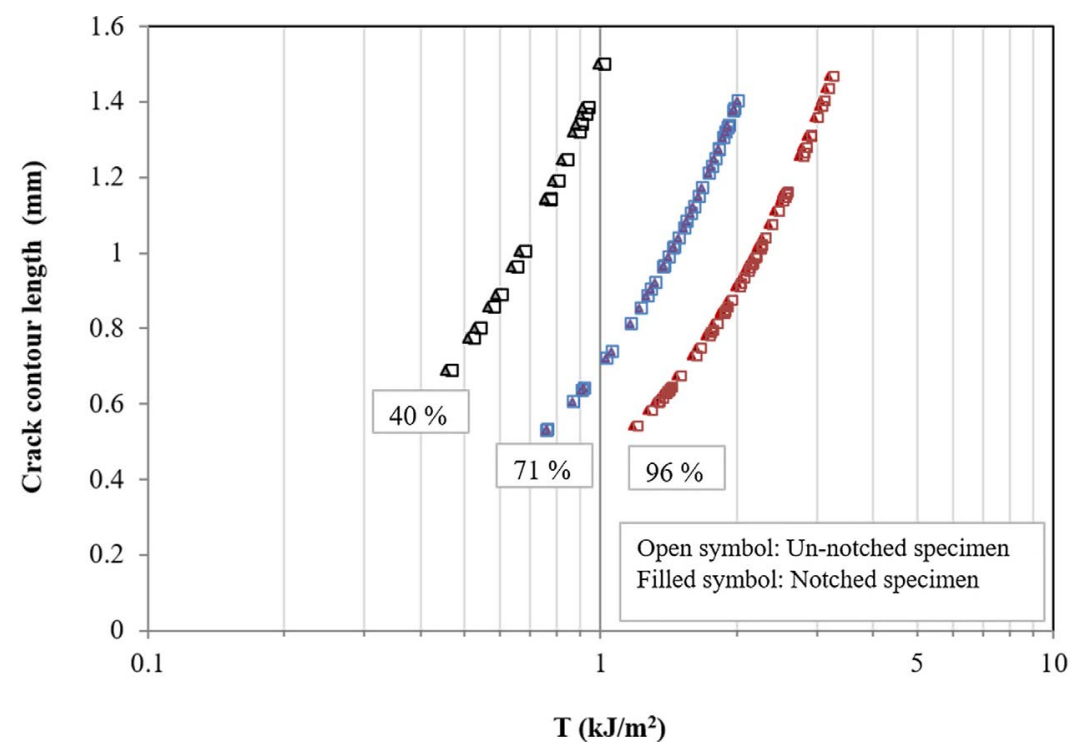

FIG. 1. - Comparison of stable propagation crack length versus tearing energy, where $W$ is taken from an notched or unnotched specimen at different dynamic strains for NR/BR control compound.

\section{RESULTS AND DISCUSSION}

\section{HYSTERESIS LOSS UNDER CYCLIC LOADING}

The breakup and reformation of the filler network within the rubber chain during cyclic deformation involves energy dissipation, often considered as being part of the mechanical hysteresis. ${ }^{32}$ Reduction in crack growth rates in $\mathrm{CB}$-filled compound, relative to unfilled rubber compound, is partially due to increase in hysteresis and other factors such as $\mathrm{CB}$ reinforcement and strain-induced crystallization. ${ }^{33,34}$ In this article, unfilled rubber refers to a rubber compound with no added filler (CB, RRP, or both). The fatigue life improvement is strongly dependent on the type and optimal loading of the $\mathrm{CB} .{ }^{35}$ Hence, hysteresis is an important characteristic when evaluating fatigue properties in terms of deformation and crack growth behavior. ${ }^{36}$ The relationship between fatigue properties, critical J-integral value, and hysteresis was studied by Kim and Jeong ${ }^{37}$ on different types of CB in NR compound. The fatigue life of the compound increases with the increase in the critical J-integral value and hysteresis. CB (N650)-filled NR containing larger aggregates or structures has lower hysteresis compared with a compound with smaller particle size and a higher surface area $\mathrm{CB}(\mathrm{N} 330)$. The hysteresis is also dependent on the temperature, ${ }^{38}$ preconditioning, dynamic strain, and frequency/strain rate. ${ }^{39}$ The result can vary according to these factors because of the viscoelastic properties of rubber. Other reinforcement factors such as strain-induced crystallization (SIC), strength anisotropy, crack deviation, and crack tip blunting have also been reported $^{40,41}$ in fracture evaluation.

The trimodal function of the Instron WaveMatrix dynamic testing software allows a minimum load (in this case, set to $1 \mathrm{~N}-0.04 \mathrm{MPa}$ ) to be applied with a displacement controlled strain superimposed, taking account of the permanent set of the samples throughout the cyclic loadings. Measurements of the hysteresis loss from the energy densities (total and strain energy) were then obtained using the same SENT specimen during the FCG test. The comparison between tearing energy calculated from $W$ of notched or unnotched specimens at different dynamic strains for NR/ BR blend control compound is demonstrated in Figure 1. Virtually no differences in the tearing 


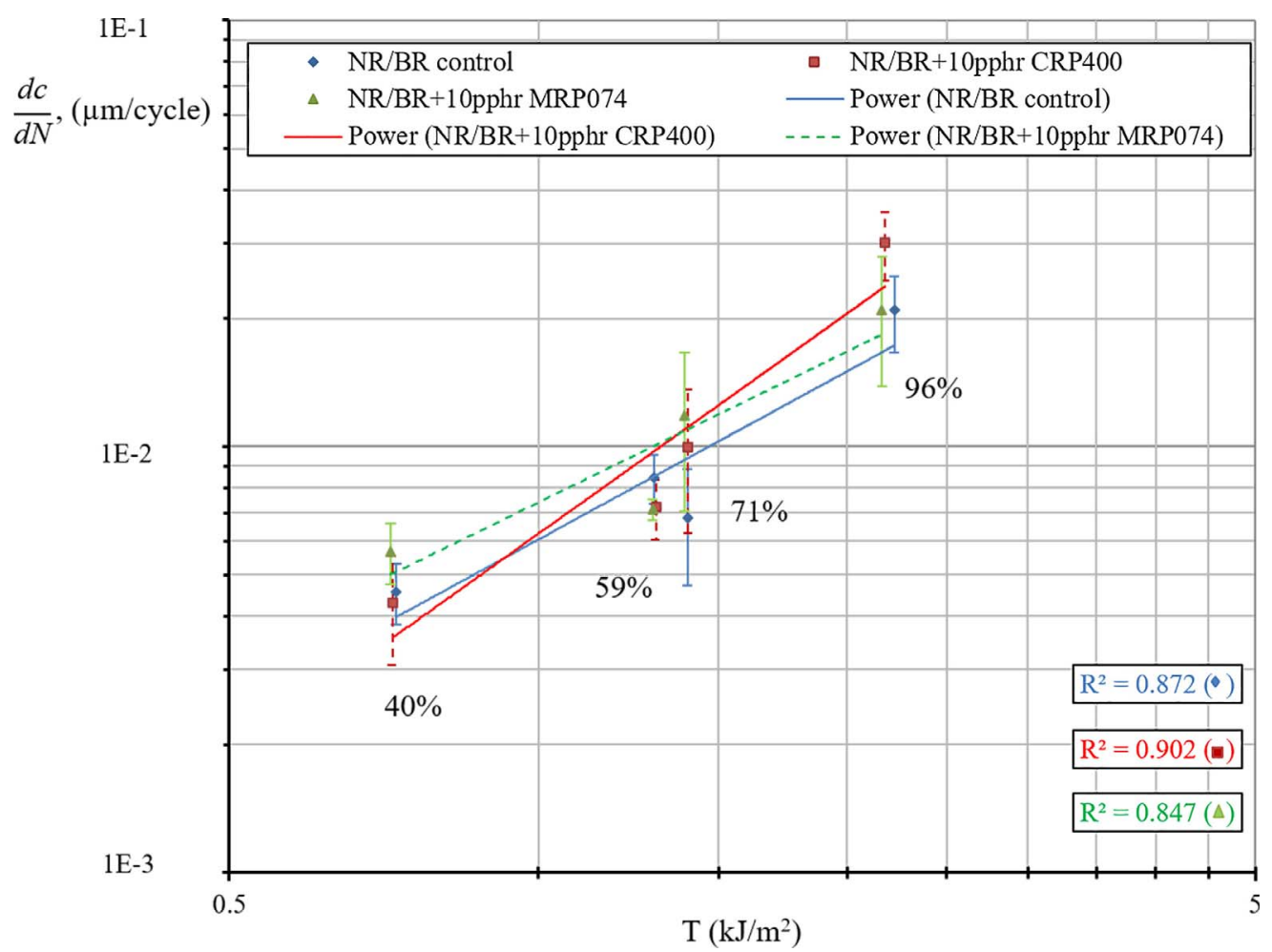

FIG. 2. - Fatigue crack growth comparison with control NR/BR compound and different RRP at 10 pphr.

energy are observed between unnotched and notched specimens. The total energy densities decrease as the cycles continue, because of cyclic stress softening of the material. ${ }^{42}$ Hence, the strain energy densities from the notched specimens during FCG are more representative of the hysteresis data of the samples tested.

\section{FCG OF NR/BR COMPOUND AND EFFECT OF CRP400 OR MRP074 FILLER}

The effect of MRP074 or CRP400 at 10 pphr loadings on FCG characteristics of the NR/BR blend compound is shown in Figure 2. Scatter in FCG results is commonly observed because fatigue is sensitive to material structure and inhomogeneities/different flaw sizes, which are difficult to control. ${ }^{43}$ In addition, the FCG rate using crack contour length shows more scatter compared with crack depth but is more closely related to the increases in the crack surfaces and tearing energy. ${ }^{44}$ Although the experimental data are scattered considerably, the $R^{2}$ of the fitting according Eq. 3 appear adequate ( $>80 \%$ ); therefore, it is reasonable to predict the dependent variables. An $R^{2}$ value as low as about $70 \%$ has been reported ${ }^{45}$ for unfilled or filled NR due to the nature of the crack in rubber matrix. Both dynamic strain energy density ${ }^{27,31}$ and hysteresis loss ${ }^{46}$ parameters could be used to evaluate the crack growth resistance of rubber compounds. The FCG results related to these parameters are discussed in the following.

At the lower tearing energy (40\% dynamic strain), the crack growth rate of CRP400-filled (10 pphr) NR/BR compound was slightly lower, but not significantly different, from the control compound because of the relatively high scatter in the results. However, both CRP400 and NR/BR compounds exhibited lower crack growth than MRP074-filled compound. Table II and Figure 3 
TABLE II

TOTAL AND STRAIN ENERGY DENSITY OF NR/BR BLEND COMPOUND (CONTROL AND CRP400- OR MRP074-FILLED COMPOUND) AT EACH LEVEL OF DYNAMIC STRAINS TESTED

\begin{tabular}{lccc}
\hline Dynamic strain, $\%$ & NR/BR & NR/BR-CRP400 & NR/BR-MRP074 \\
\hline Total energy density, $W_{a}, \mathrm{~N} / \mathrm{mm}^{2}$ & & & \\
40 & $0.142 \pm 0.003$ & $0.137 \pm 0.001$ & $0.141 \pm 0.001$ \\
59 & $0.265 \pm 0.002$ & $0.257 \pm 0.002$ & $0.246 \pm 0.022$ \\
71 & $0.348 \pm 0.002$ & $0.341 \pm 0.005$ & $0.345 \pm 0.006$ \\
96 & $0.542 \pm 0.009$ & $0.534 \pm 0.010$ & $0.535 \pm 0.005$ \\
Strain energy density, $W_{s}, \mathrm{~N} / \mathrm{mm}^{2}$ & & & \\
40 & $0.123 \pm 0.002$ & $0.118 \pm 0.0002$ & $0.121 \pm 0.0011$ \\
59 & $0.225 \pm 0.001$ & $0.218 \pm 0.001$ & $0.232 \pm 0.024$ \\
71 & $0.298 \pm 0.002$ & $0.292 \pm 0.005$ & $0.295 \pm 0.005$ \\
96 & $0.479 \pm 0.008$ & $0.465 \pm 0.008$ & $0.469 \pm 0.005$ \\
\hline
\end{tabular}

show the total and strain energy densities for control and MRP074- or CRP400-filled NR/BR compounds under various strains. By examining the plots, considering the data scattering, there are virtually no differences between energy values for all compounds, but Table II shows that at $40 \%$ or 59\% dynamic strain amplitudes, CRP400 compound exhibits lower strain energy densities compared with the control and MRP074-filled compound within the experimental error. The lower strain energy density corresponds to a reduced energy available for crack propagation, which would partially explain the lower crack growth of CRP400-filled NR/BR compound at $40 \%$ or $59 \%$ dynamic strain.

The addition of filler has been shown to increase hysteresis ${ }^{47}$ in the rubber matrix, with the extent depending on the type and amount of filler. Higher hysteresis could reduce the energy available for crack propagation ${ }^{35}$ and is important for rubber reinforcement. This indicates that the fracture resistance of rubber is not only dependent on the strain energy density (crack driving force) but also on the energy dissipated around the crack tip. ${ }^{48}$ Figure 4 shows the absolute and relative hysteresis loss for NR/BR- or RRP-filled compound at each of the dynamic strain levels tested. The increase in dynamic strain increases the absolute hysteresis of the rubber network (Figure 4a). At $40 \%$ dynamic strain, there was no significant influence on the absolute value of hysteresis loss of NR/BR control or either RRP-filled NR/BR compounds. However, the relative hysteresis loss
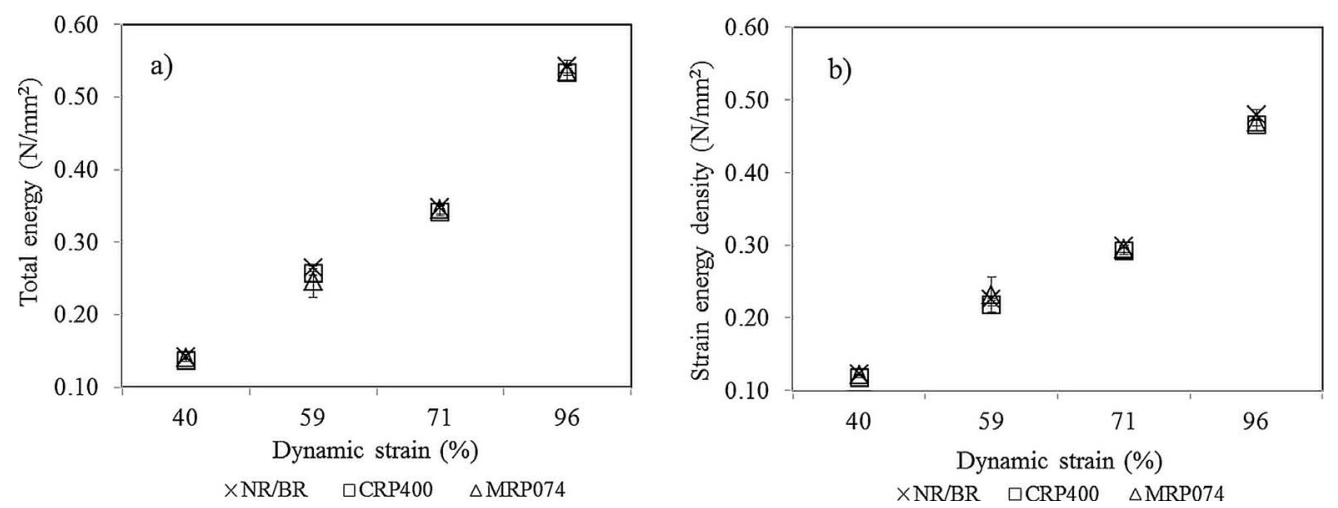

FIG. 3. - Total and strain energy densities of NR/BR blend compound (control and CRP400- or MRP074-filled compound) at each level of dynamic strains tested. 

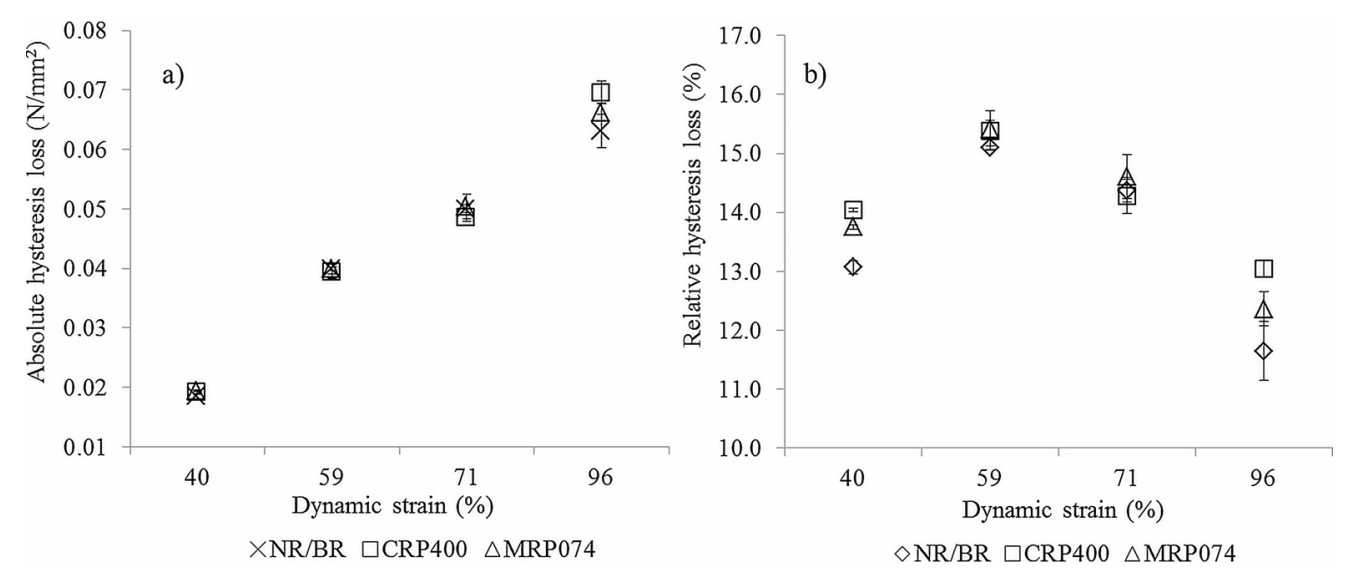

FIG. 4. - (a) Absolute hysteresis loss and (b) relative hysteresis loss of NR/BR blend with 10 pphr of CRP400 or MRP074 at each level of dynamic strains tested.

showed different trends. The possible explanation might be the multiple energy dissipative mechanisms ${ }^{35}$ that occur around the crack tip. As expected, both RRP-filled compounds have increased relative hysteresis loss because of the additional filler in the NR/BR compound (Figure 4b). The cure characteristics of NR/BR-, CRP400-, or MRP074-filled compounds were previously studied. ${ }^{25} \mathrm{NR} / \mathrm{BR}$ control compound had higher relative crosslink density than the NR/BR phase of the RRP compounds, as migration of curatives from the virgin to the RRP compound caused reduction in the crosslinking in both the CRP400- and MRP074-filled matrix. The higher crosslinking could reduce the ability of the rubber to dissipate energy through hysteresis.

Another possible explanation is that the CRP400 compound showed higher relative hysteresis loss compared with the MRP074 compound because of the irregular (convoluted) surface of CRP400, as reported in an earlier study. ${ }^{25}$ The irregular surface of CRP400-filled compound provides greater surface area and a stronger interface between the particles and the rubber matrix. A stronger interface interaction/bonding in this work was defined as the interaction level between the rubber and filler that could restrict the mobility of the rubber molecules on the filler surfaces. Thus, more contact with $\mathrm{CB}$ and hysteresis within the CRP400 fillers creates more internal friction, contributing to higher relative hysteresis. Combined effects of additional hysteresis for the CRP400 compound could reduce the crack growth rate.

At 71\% dynamic strain, the FCG of NR/BR is lower compared with the CRP400- or MRP074filled compounds. The weak bonding between the matrix and RRP can lead to a weak interface for failure initiation. The migration of sulphur ${ }^{25}$ apart from the weak bonding has also been suggested as a cause for this reduction in mechanical and FCG test of the RRP-filled compound. RRP might also increase the stress concentration and reduced strength at the crack tip, consequently resulting in the reduction of the SIC effect.

The increase in absolute hysteresis loss due to introduction of RRP is expected when part of the strain energy density is dissipated as heat while the other parts act as a crack/fracture driving force. ${ }^{49}$ Also, the relative hysteresis loss passes through a maximum then decreases with increasing dynamic strain amplitudes. At $50 \%$ or $71 \%$ dynamic strain, there is no significant difference between MRP074, CRP400, or control NR/BR values. The overlapping trends of the relative hysteresis loss for all compounds is not yet fully understood but could be attributed to the multiple dissipative processes occurring at the crack tip. ${ }^{35}$ Additional dissipation may be attributed to the SIC effect. ${ }^{33}$ The SIC effect is believed to be higher at $71 \%$ compared with $40 \%$ dynamic strain, as deviation from the straight trend line. SIC increases with increasing strain amplitude and causes 
increased anisotropy of the material strength. ${ }^{19}$ At higher dynamic strain during cyclic loading, strain-induced crystallization of NR will create an area at the crack tip that will prevent the crack growth in that direction. Higher SIC at the crack tip enhances crack tip blunting and branching. ${ }^{32}$ The splitting into two or more smaller shared crack tips reduces the total tearing energy available for each individual crack. ${ }^{50,51}$

At $96 \%$ dynamic strain, a lower relative hysteresis loss was observed for all tested samples compared with lower dynamic strain (40\%). During this stage, the molecular chain (filler-filler bonds and weak rubber-filler bonds) was broken down and the mobility reduced. ${ }^{39}$ As cycles continued, less energy was required for the breakdown of the filler-filler and rubber-filler network, leading to reduced energy dissipation compared with lower dynamic strain. Another possible reason is that the relative hysteresis is dependent on the degree of crystallinity during cyclic loading and unloading. ${ }^{52}$ The reduction of the SIC at $96 \%$ dynamic strain reduces the relative hysteresis loss.

At higher tearing energy levels (96\% dynamic strain), the crack growth rates changed to be ranked CRP400 > MRP074 > control NR/BR compound. There could be a competition between SIC and the crack growth. Higher crack growth rate reduces both the threshold tearing energy and the ability to crystallize ${ }^{53}$ at the crack tip. By increasing the amplitude, it is suggested that the ultimate properties of the CRP400 decrease faster than in MRP074, which increases the crack growth rates of CRP400. This supports the strength dependence on the crack growth rate at higher tearing energy ${ }^{53}$ found for CRP400. In addition, weak bonding between the RRP filler and rubber matrix creates more microvoid sites, which initiate fatigue failure. These microvoids are believed ${ }^{54}$ to increase in size with increasing dynamic strain amplitudes and contribute to the higher crack growth of the RRP-filled matrix.

The CRP400-filled NR/BR showed significant absolute hysteresis loss at $96 \%$ dynamic strain. Similarly, the CRP400-filled compound exhibited higher relative hysteresis loss compared with MRP074-filled or control NR/BR. Higher hysteresis dissipates heat and increases the neighboring network temperature, which can accelerate molecular chain rupture and suppress the SIC effect $^{55}$ at the crack tip. A lower relative hysteresis loss for NR/BR or with MRP074 filler probably reflects a better transmission of the stress from matrix to the neighboring particles. Further investigation is needed to confirm this assumption.

\section{MORPHOLOGY OF FRACTURE SURFACES FROM FCG TEST AT DIFFERENT TEARING ENERGIES}

Evaluation of the fracture surface on the microscopic scale after fatigue failure is important for identification of crack growth regime, location of crack initiation, or possible flaw information. Crack growth mechanisms and microscopic examination of the fracture surfaces from the fatigue test have been reported for NR. ${ }^{17,19,49,50,56}$ The sample formulations, method of testing, and focus of interest were different in each case. Nevertheless, some observations or similar fracture mechanisms occurring on the fracture morphology were also seen to take place in the NR/BR blend due to the dominant factor of NR and its unique properties of SIC. Le Cam et al. ${ }^{16}$ described the rough "twisted knots" at the stable crack propagation zone as "wrenching" due to stretched ligaments, which break and retract. For unfilled NR, at low and higher tearing energy, Weng et al. ${ }^{49}$ used the terms surface peeling and buckling and ligaments breakage, respectively, to describe the cracking morphology. The microstructure of the fatigue damage changes at different strain amplitudes ${ }^{19}$ and is also dependent on factors such as velocity of crack growth, ${ }^{19,57}$ strain rates, ${ }^{58}$ strain crystallization ${ }^{59}$ (polymer type), environmental factors (oxygen, ozone, ultraviolet-light, etc.), and mechanical (stretching, triaxial stresses) ${ }^{59}$ conditions.

The crack roughness is a characteristic of the crack growth rate. ${ }^{50}$ The higher ratio of the macroscopic rough to smooth fracture surface indicates stronger resistance to crack growth. It is 
reported $^{49}$ that the microscopic smooth surfaces reflected less energy dissipation compared with microscopically rough crack surfaces. Quantitative measurement of roughness is not currently a simple task because of variation of fracture depths and irregular cracking structures. Hence, in this work, qualitative observation was made at different tearing energies to understand the relation of the roughness and crack resistance mechanism in the NR/BR blend and the effect of CRP400 or MRP074.

In an earlier study ${ }^{60}$ on the morphology of fracture samples from FTFT, it was shown that the two distinct features (rough and macroscopically smooth textures) are present in unfilled NR or NR/ BR blend compound. The difference is that the proportion of "microscopically rough surfaces" largely dominates the surface failure of NR/BR but is less dominant in the NR compound. This section discusses some energy density-as well as material-related phenomena of crack propagation at the crack tip until failure, where the location of the crack initiation is unknown in the FTFT. All SEM pictures of fatigue fracture surfaces shown are representative for their testing condition and depict the corresponding crack morphology pattern in the clearest form.

Lower Tearing Energy (FCG Test). - At lower dynamic strain amplitude (40\%) or tearing energy, the crack fracture morphology during the FCG test shows different crack propagation regions: (a) stable crack propagation, (b) unstable crack propagation, and (c) catastrophic propagation zone (Figure 5). The V shape near the crack tip features a shallow valley, which consists of a striation of overlapping microscopic rough "twisted knots." This V shape reflects the diagonal direction of the crack path, and "A" corresponds to the crack tip area where the main breakage of chains/ligaments would take place. A higher magnification of the fracture morphology under lower tearing energy is depicted in Figure 6. Beurrot et al. ${ }^{56}$ attributed the fracture's "leaves" shape to the short deviated cracks developed from the main crack path, known as the "crackbranching phenomena," during fatigue crack propagation for CB-filled NR. The microscopically rough structure reflects the breaking and retraction of the ligaments. ${ }^{17,61}$ The chain-breaking process ahead of the crack tip is governed by the bond strengths and the alignment or crosslink of the molecular chains. ${ }^{53}$ Under constant strain amplitude, depending on the threshold energy of the rubber, the repeated deformation process probably contributes to the buildup/overlapping layered structure when the cycles continue. This could explain why the striation morphology (zig-zag striation or up-and-down pattern cracks proposed by Flamm et al. ${ }^{19}$ and Hamed et al. ${ }^{41}$ ) is not apparent at lower tearing energy. This twisted knots layered structure contributes to the roughness at the crack tip. This microstructure corresponds to the stable crack propagation of the FCG testing. Between these layers, distinct cracking lines were observed, which probably indicates breaking of some molecular chains. Weng et al. ${ }^{49}$ proposed coalescence of microvoids to form crazes for unfilled NR at lower tearing energy. This partially explains the cracking line. In this study, two types of roughness are proposed.

In the first type, at lower tearing energy, the microscopic roughness was attributed to the layered structure's "twisted knots" before the molecular chains/ligaments ruptured at the crack tip. The second type of microscopic roughness was attributed to the crack branching or splitting after the rupture of molecular/ligaments at the crack tip. As the crack length increases, the crack splitting or branching becomes more obvious with a widened crack opening (highlighted with a dotted line), as shown in Figure 5b,c.

Depending on the characteristic of the flaws, temperature, strain amplitude, or strength anisotropy under cyclic loading conditions, the transformation from stable crack propagation to the unstable region occurs once the ligaments or main molecular chains were fractured. Once the dynamic catastrophic tearing energy has been exceeded, for the CB-filled compound, catastrophic failure was delayed compared with unfilled rubber compound. The presence of $\mathrm{CB}$ filler provides additional reattachment sites for the broken network ligaments/chains. ${ }^{32}$ In the unstable crack 

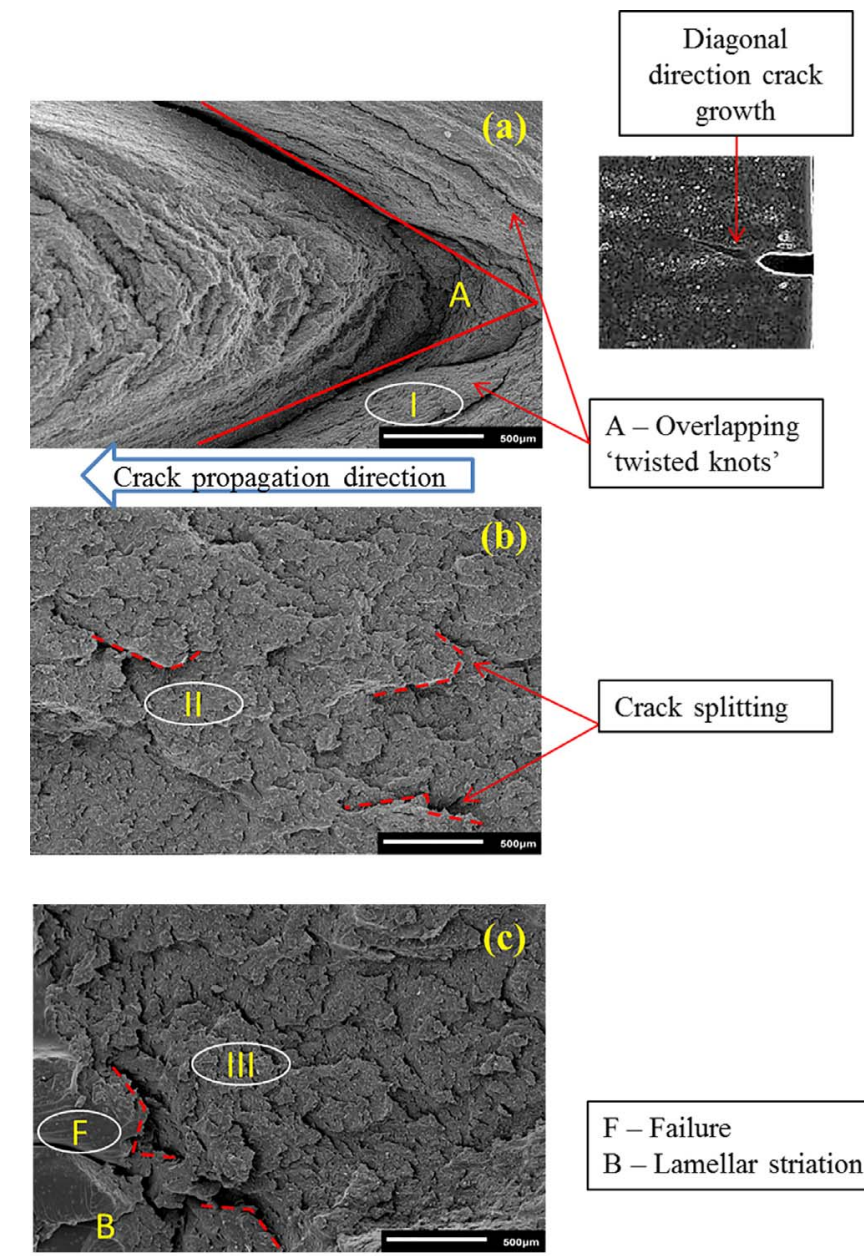

F - Failure

B - Lamellar striation

I - Stable crack propagation
II - Unstable crack propagation
III - Catastrophic propagation

FIG. 5. - Fracture morphology at 40\% dynamic strain amplitude for NR/BR blend compound showing different crack propagation regions: (a) stable crack propagation, (b) unstable crack propagation, and (c) catastrophic propagation zone.

propagation (II), the crack growth is much faster and crack lines appear to be much broader and rougher on the macroscopic scale.

Before the final fracture $(\mathrm{F})$, the transition from a rough to smooth surface was observed. The "fracture leaves" structure can still be observed before the final fracture. There is also a small area of striation morphology, which probably indicates relatively higher crack growth rates before the final fracture. This type of microstructure is more obvious at higher tearing energy. ${ }^{17,57}$

Higher Tearing Energy (FCG Test). — Figure 7 shows the representative SEM images of fracture samples for NR/BR blend compound after FCG with stable crack propagation (I), transition (unstable region) (II), and catastrophic crack propagation region (III) under the strain amplitude of $15 \mathrm{~mm}$ (96\% dynamic strain). At higher tearing energy, crack growth and ligament break up are much faster than at lower amplitude. Thus, shortly after the ligament breakup (area of "V" shape), the roughening crack tip is reduced, resulting in much broader fracture leaves. This 

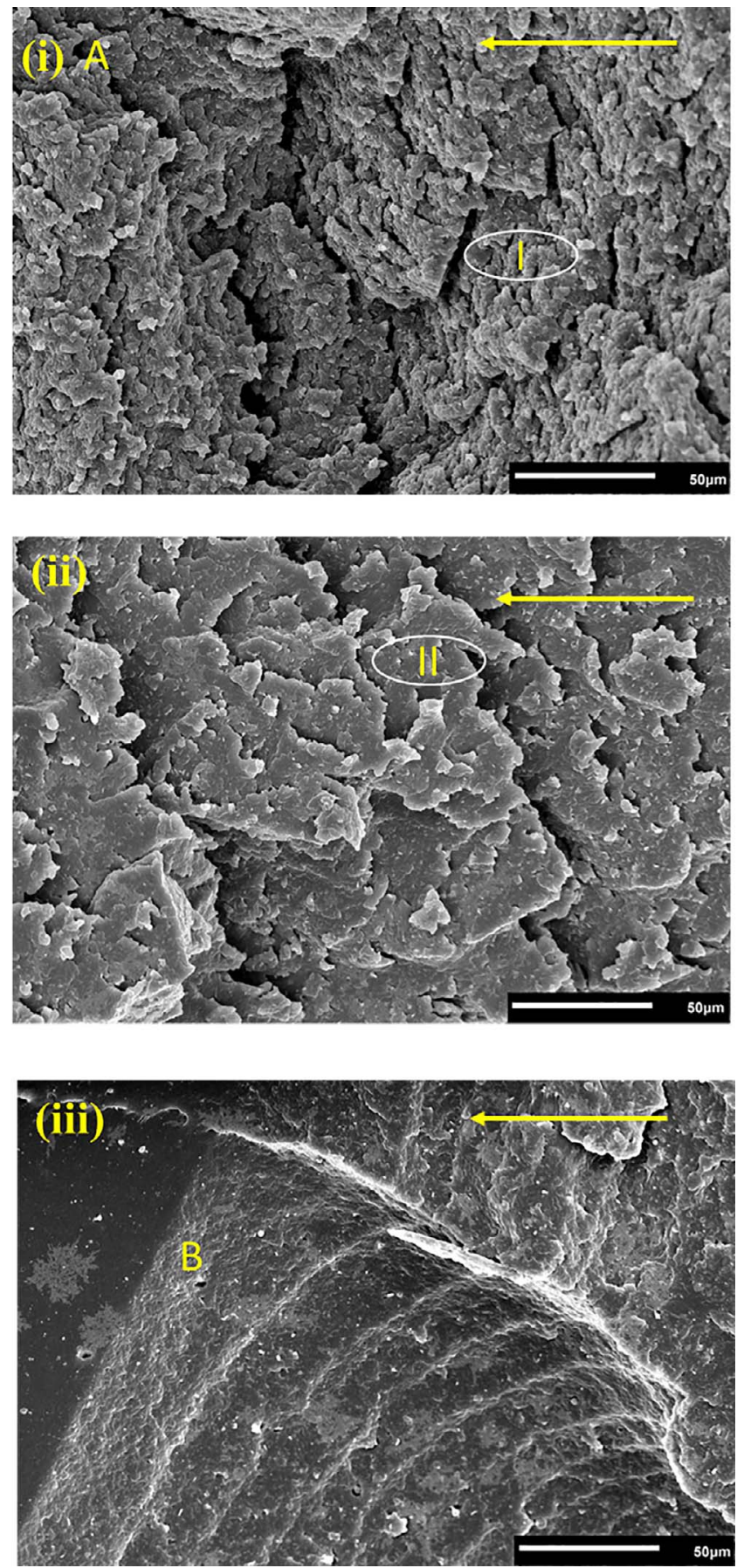

FIG. 6. - A higher magnification of Figure 5. (i) Stable crack propagation zone (A), (ii) unstable crack propagation, (iii) striation before final fracture (B) (A and B are located in Figure 5a and c). The horizontal arrow indicates the crack propagation direction. 

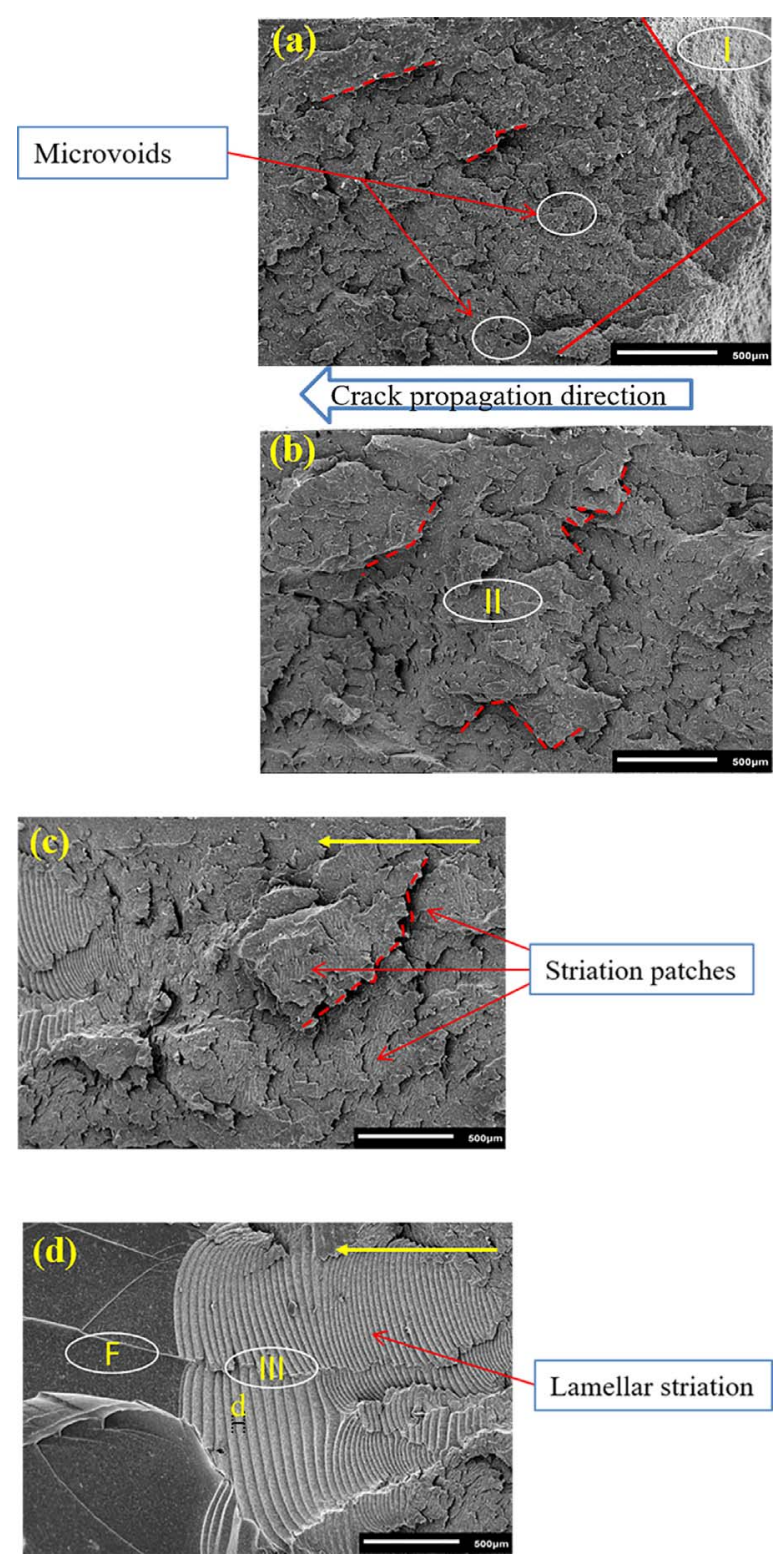

FIG. 7. - Fracture morphology at $96 \%$ strain amplitude for the NR/BR blend compound showing different crack propagation regions: (a) stable crack propagation, (b) transition. Fracture morphology at $96 \%$ dynamic strain for the NR/BR blend compound showing different crack propagation regions: (c, d) catastrophic propagation zone.

corresponds to a competition between higher crack growth rate and the effect of SIC as discussed earlier.

Crack diversion or splitting is observed and increases with the number of cycles. Deeper cracking lines behind the fracture leaves are visible compared with the preceding crack growth (Figure 7b compared with Figure 7a). Crack diversion, highlighted by the red dotted line, is observed at stage II and before the striation morphology (Figure 7c). Microcracks/voids are more obvious at higher strain amplitude and in agreement with Flamm et al. ${ }^{19}$ 

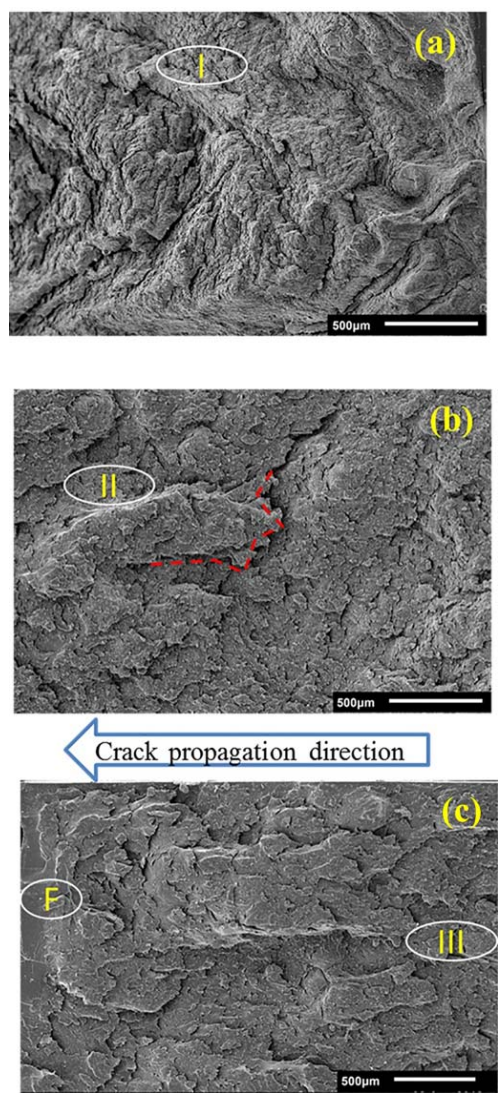

FIG. 8. - Fracture morphology at 40\% strain amplitude for the CRP400-filled NR/BR blend compound showing different crack propagation regions: (a) stable crack propagation, (b) transition, and (c) catastrophic propagation zone.

In the catastrophic region (Figure 7c,d), an area with considerable striation morphology and highly elongated lamellar features before the final fracture was observed. Several areas of striation patches were also visible. The increasing tearing energy appears to increase the crack growth rate and the striation sizes. The distance $d$ between the two striations increases from approximately 20 $40 \mu \mathrm{m}$ to $50-60 \mu \mathrm{m}$ it approaches the failure region (Figure 7d), which follows a similar trend of striation morphologies as reported by Ruellan et al. ${ }^{18}$ This type of fracture morphology has also been observed in NR under severe loading by other authors. ${ }^{17,19}$ The characteristics of striation morphology are still unclear, but a full discussion of these characteristics is beyond the scope of this study.

CRP400- or MRP074-Filled NR/BR Compound. - It is recognized ${ }^{32,50}$ that the inclusion of particulate fillers, such as $\mathrm{CB}$, promotes tear deviation and crack splitting and thus increases fracture surface roughness in comparison with gum/unfilled rubber compound. ${ }^{58}$ Figures 8 and 9 show the effect of CRP400 and MRP074 at $10 \mathrm{pphr}$ loading on the fracture morphology of FCG for NR/BR blend compound at $6 \mathrm{~mm}$ strain amplitude (40\% strain). The addition of RRP increases the roughness of the fracture surface relative to that of the CB-filled NR/BR compound without RRP filler, which is in apparent contrast to Figure 5.

In the earlier discussion, it was shown that CRP400-filled compound has lower crack growth rates at a lower tearing energy. From a microscopic viewpoint, more rough fracture surfaces are observed with CRP400 compound, which can be seen in Figure 8b,c compared with Figures 5 and 9 

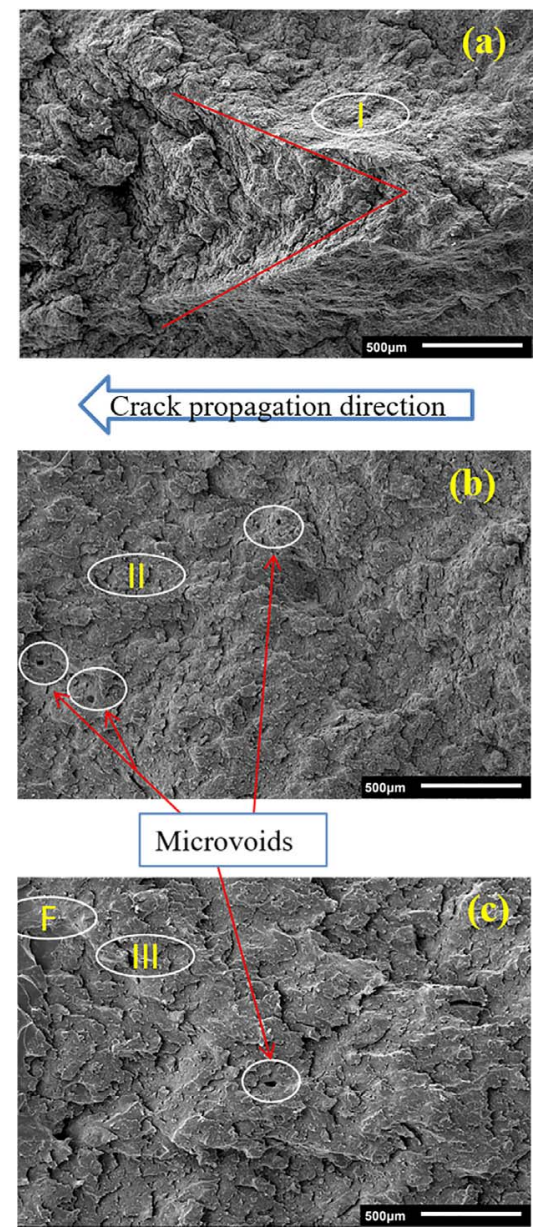

FIG. 9. - Fracture morphology at 40\% strain amplitude for the MRP074-filled NR/BR blend compound showing different crack propagation regions: (a) stable crack propagation, (b) transition, and (c) catastrophic propagation zone.

for the control and MRP074-filled compound. The microscopic rougher surfaces correspond to more crack splitting, which is in agreement with the study by Asare. ${ }^{51}$ The crack splitting and diversion are reflected on the fracture surfaces as an uneven, rough, "hilly" structure. More hilly structures and greater cracking depths are observed for CRP400- than for MRP074-filled compound. The creation of rough crack surfaces/additional surface area around the irregular larger particles of CRP400, as shown in Figure 10a, $\mathrm{b}^{25}$ in contrast to MRP074 (Figure 10c,d), will require additional energy, resulting in slower crack growth rates, and the longer crack path contributes to higher relative hysteresis, as discussed in the "FCG" section. Figure 11 shows the macroscopic profiles of fracture surfaces for CRP400-filled compound at $40 \%$ and $96 \%$ dynamic strain amplitudes, which demonstrate more crack path deviations in comparison with MRP074 and control compound.

More microvoids are visible for both RRP fillers (Figure 12) than in the control NR/BR compound (Figure 5). The embedded CRP400 particles and layers around the particles, compared with clear "voids" for MRP074, supports the previous assumption of stronger bonding between the CRP400 particles and rubber matrices than for MRP074 filler. 


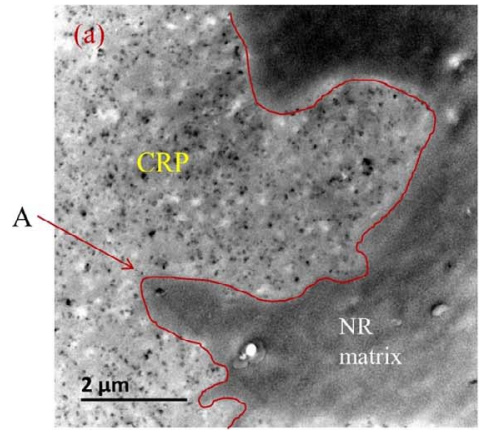

NR +10 pphr CRP400

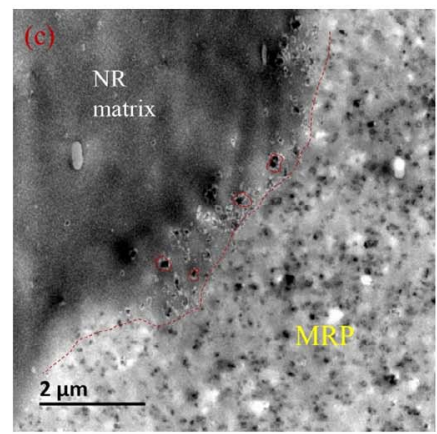

$\mathrm{NR}+10$ pphr MRP074

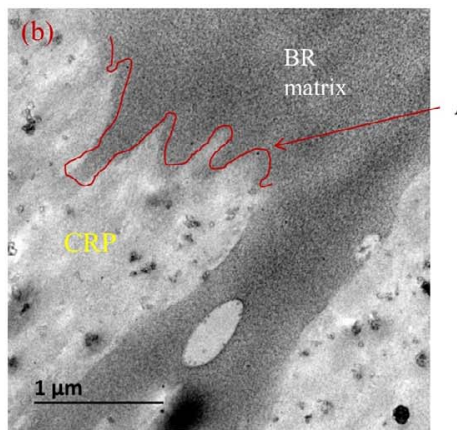

$\mathrm{BR}+10$ pphr CRP400

A - irregular/convoluted shape

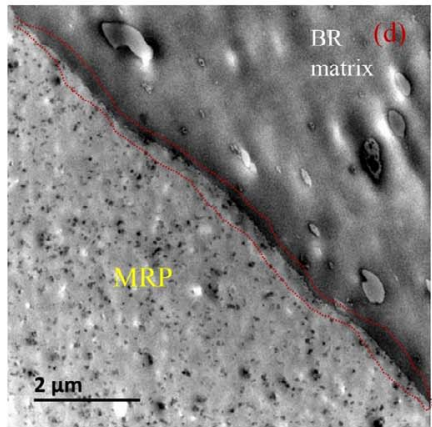

BR + 10 pphr MRP 074

FIG. 10. - Transmission electron microscopy (TEM) network visualization micrographs from a previous publication ${ }^{25}$ of stained (a) NR+10 pphr CRP400, (b) BR+10 pphr CRP400, (c) NR+10 pphr MRP074, and (d) BR+10 pphr MRP074 sectioned from unfilled rubber vulcanizates.

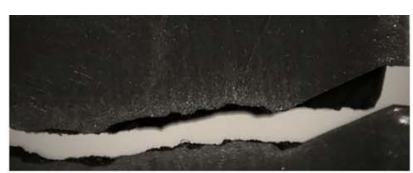

a) NR/BR-control-40\%

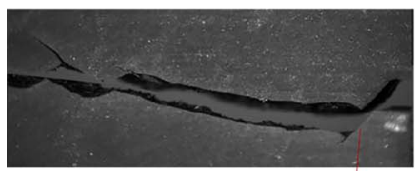

(i)

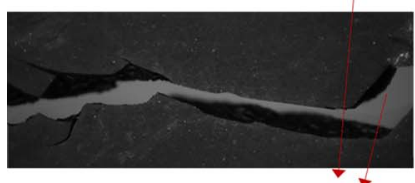

(ii)

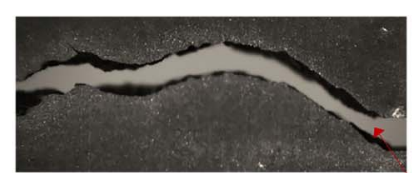

b) NR/BR-CRP400-40\%

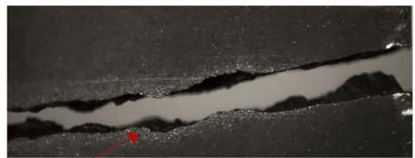

c) NR/BR-MRP074-40\% Crack path deviations

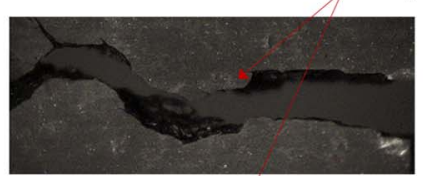

(i)

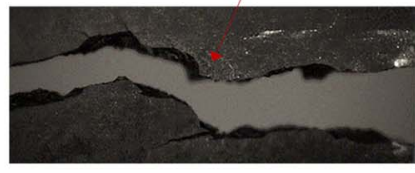

(ii)

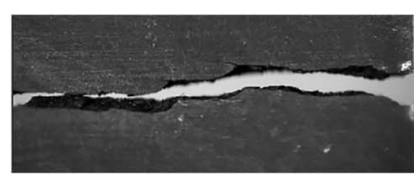

(i)

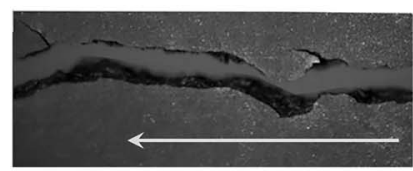

(ii)

d) NR/BR-control-96\%

e) NR/BR-CRP400-96\%

FIG. 11. - Macroscopic profiles of fracture surfaces at $40 \%$ and $96 \%$ dynamic strain for NR/BR- and RRP-filled NR/BR compounds showing crack path deviations. The horizontal arrow indicates the crack propagation direction. 


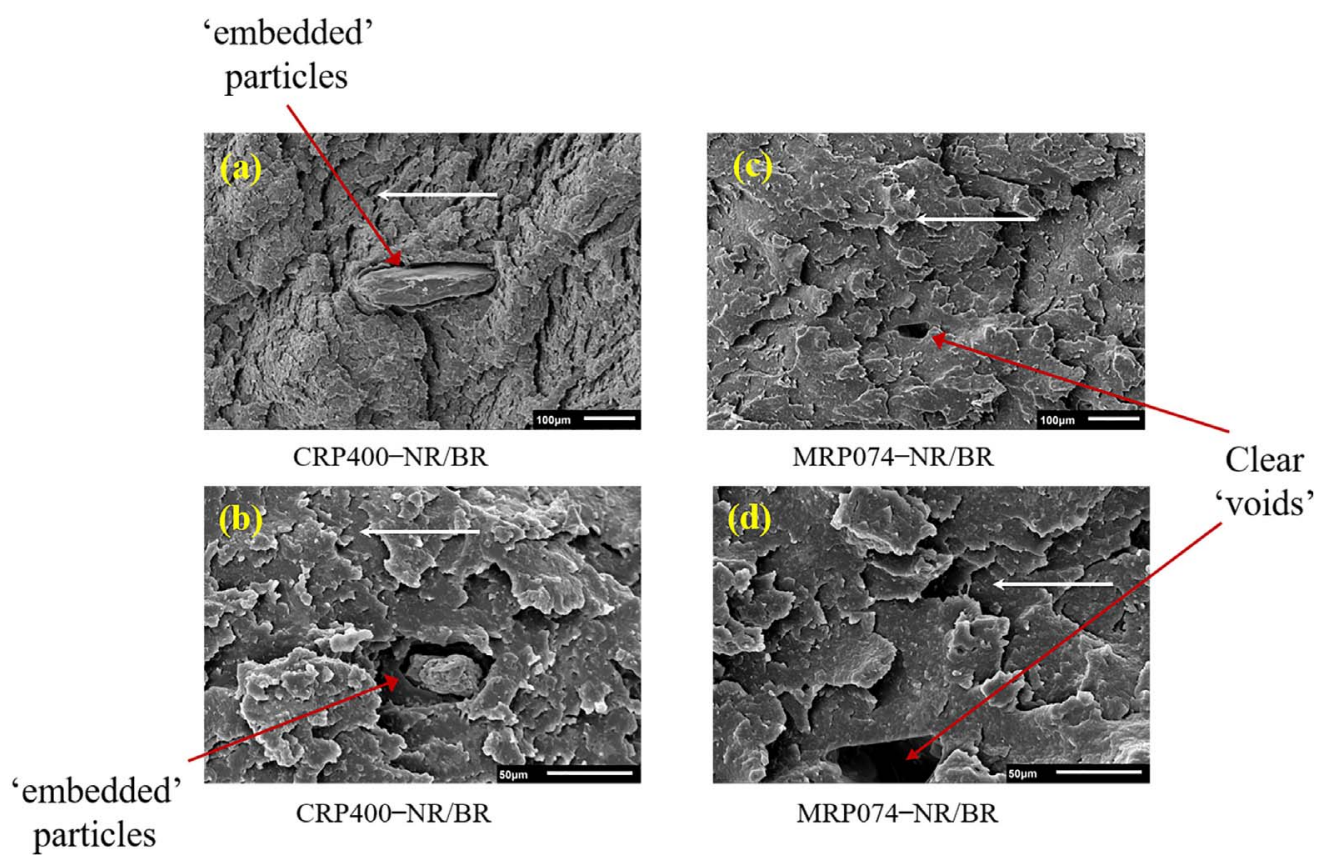

FIG. 12. - Microvoids in the (a,b) CRP400 NR/BR and (c,d) MRP074 NR/BR compounds at 40\% strain amplitude at different magnifications (the horizontal arrow indicates the crack propagation).

The fracture surfaces at higher strain amplitude (96\% dynamic strain) for CRP400 or MRP074 are shown in Figures 13 and 14, respectively. There is no obvious V shape at the crack tip fracture surfaces, which corresponds to the lateral crack pathway. The crack growth was much faster, as indicated by the broader "fracture leaves," in contrast to Figures 8a and 9a, after the molecular chains at the crack tip were fractured. As stated earlier, weak bonding between the RRP filler and rubber matrix likely creates more microvoid sites that increase in size with increasing dynamic strain amplitudes ${ }^{19}$ for RRP (MRP074 or CRP400)-filled compound. This could increase the stress concentration and hence reduce the strength at the crack tip, resulting in the indistinct $\mathrm{V}$ shape. Before the final fracture, the striation morphology observed for the control compound was also visible in RRP-filled compounds.

The striation morphology patterns were distorted, and some were detached. The detachment and distortion were substantial in the CRP400-filled compound. This is probably due to extensive crack splitting and diversion around the CRP400 particles. Severe crack splitting was expected with the larger particle size of CRP400 and stronger interface compared with MRP074. When crack splitting occurs, one crack exhibits a higher energy release rate and will advance or become part of a larger crack. Cracks that have a lower energy release rate will stop growing. ${ }^{51,62}$ This will leave several crack lines as its "footprint" in the fracture morphology. Fracture images of crack splitting before the final fracture corresponding to several crack lines behind the fracture leaves can be seen in Figure 15, which confirms the previous explanation.

\section{CONCLUSION}

By using the trimodal function of Instron WaveMatrix dynamic testing software, a minimum load is applied to avoid sample buckling. A displacement controlled strain is superimposed, 

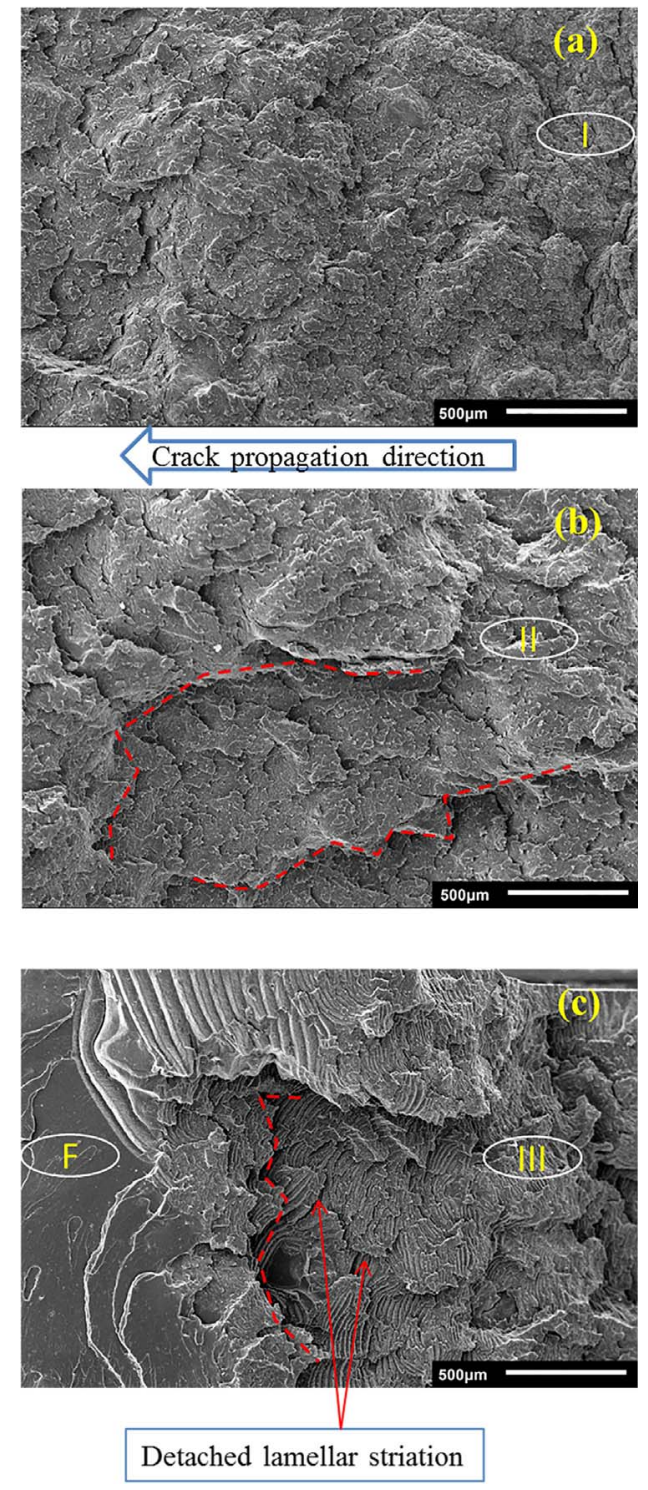

FIG. 13. - Fatigue fracture morphology of $10 \mathrm{pphr}$ CRP400-filled NR/BR blend at $96 \%$ dynamic strain: (a) stable crack propagation, (b) transition, and (c) catastrophic region.

compensating for the permanent set of the samples throughout the experiments. Hence, both relative and absolute hysteresis loss measurements using strain energy density from the SENT specimen during the FCG test are possible and produce more representative hysteresis data for the samples tested.

At lower tearing energy (40\% dynamic strain), CRP400-filled compound showed slower, but not significantly different, crack growth rates, than in the NR/BR control compound. The compound exhibited lower strain energy density compared with MRP074 or control NR/BR compound. The fracture resistance of rubber is not only dependent on the strain energy density (crack-driving force) but also energy dissipated around the crack tip. The possible combined effects 


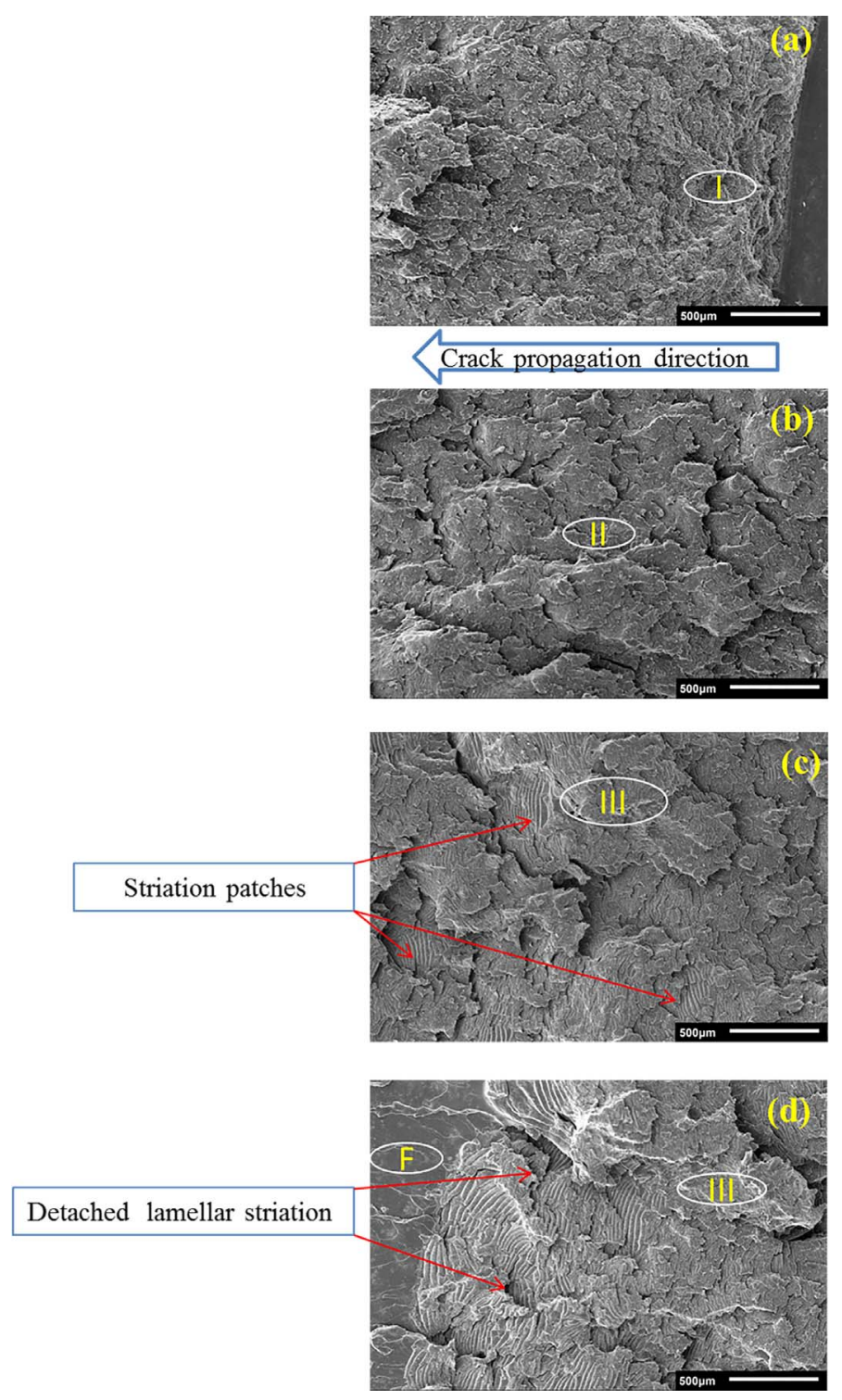

FIG. 14. - Fatigue fracture morphology of $10 \mathrm{pphr}$ MRP074-filled NR/BR blend at 96\% dynamic strain: (a) stable crack propagation, (b) transition, and (c,d) catastrophic region.

include differences in crosslink density and the relative hysteresis loss. The irregular surface of CRP400 provides greater surface area for bonding and a stronger interface between the particles and rubber matrix. There is a longer crack path around CRP400 particles and hence more new surface energy compared with either smaller, microscopically smooth MRP074-filled or control NR/BR compound.

The FCG rate of NR/BR is slightly lower compared with CRP400- or MRP074-filled compound (71\% and 96\% dynamic strain). Weak bonding between the RRP filler and rubber matrix creates more microvoid sites, which initiate fatigue failure. These microvoids are believed to increase in size with increasing dynamic strain amplitudes and probably contribute to higher crack 


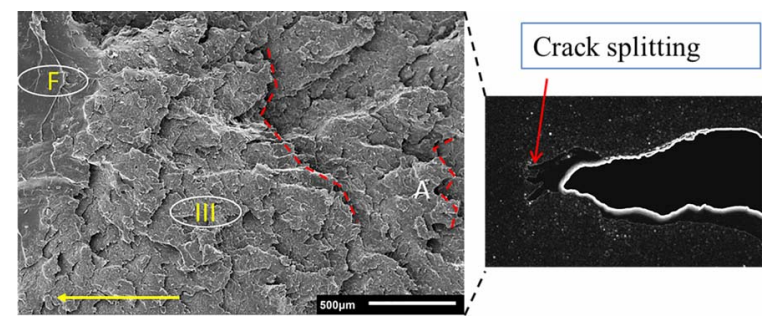

FIG. 15. - FCG fracture morphology of $10 \mathrm{pphr}$ MRP074-filled NR/BR blend at 59\% strain amplitude showing that the crack splitting corresponds to several crack lines behind the fracture "leaves" before final fracture (the horizontal arrow indicates the crack propagation direction). $\mathrm{F}$ indicates failure; III, catastrophic crack propagation region.

growth of the RRP-filled matrix. SIC effect reduction could be another factor, whereby the RRP increases the stress concentration and reduces the strength at the crack tip.

The crack fracture morphology at different tearing energies provides valuable insight into the FCG mechanisms of NR/BR blend control and CRP400- or MRP074-filled compound. Crack tip blunting as well as crack splitting or deviation at the crack tip are clearly important aspects of the resistance to the crack propagation. However, they cannot explain the overall performance of the total fatigue life. Total fatigue life comprises of (1) fatigue initiation from various sources of flaws, (2) crack propagation within the bulk materials, and (3) catastrophic crack growth. Differences in the microstructure at varied tearing energies also showed a dependency of the crack growth microstructure on the tearing energies.

Overall, although the average CRP400 particle diameter is about a factor five larger in one dimension than MRP074, the CRP400 compound exhibits a lower crack growth rate in the technically important low strains/tearing energy region. The "rougher"/irregular surface of CRP400 appears to be a more important factor than the particle size of MRP074 for the FCG performance, especially at lower strains. Nevertheless, at higher strain (96\%), higher absolute and relative hysteresis is slightly detrimental to the FCG rate of CRP400-filled compound. The performance of MRP074-filled compound possibly could be improved by using optimal CB loading and adjusting the curing systems and will be considered for future study.

\title{
ACKNOWLEDGEMENT
}

This research was funded by the Malaysian Rubber Board. The authors gratefully acknowledge Paul Brown, Kenneth Halls, and Paul Gladwin (Tun Abdul Razak Research Centre), Terry Richards (School of Engineering), and Glenn Harper (Plymouth Electron Microscopy Centre), University of Plymouth, for their technical assistance during experimental work of this research.

\section{REFERENCES}

\author{
${ }^{1}$ A. N. Gent, P. B. Lindley, and A. G. Thomas, J. Appl. Polym. Sci. 8, 455 (1964). \\ ${ }^{2}$ R. Rivlin and A. G. Thomas, J. Polym. Sci. 10, 291 (1953). \\ ${ }^{3}$ A. A. Griffith, Philos. Trans. R. Soc. London Ser. A 221, 163 (1920). \\ ${ }^{4}$ T. D. Sreeja and S. K. N. Kutty, Polym. Plast. Technol. Eng. 39, 501 (2000). \\ ${ }^{5}$ B. Maridass and B. R. Gupta, J. Elastom. Plast. 38, 211 (2006). \\ ${ }^{6}$ S. Ramarad, M. Khalid, C. T. Ratnam, A. L. Chuah, and W. Rashmi, Prog. Mater. Sci. 72, 100 (2015).
}


${ }^{7}$ S. O. Movahed, A. Ansarifar, and S. Estagy, Rubber CHEM. TeChnOL. 89, 54 (2016).

${ }^{8}$ S.-C. Han and M.-H. Han, J. Appl. Polym. Sci. 85, 2491 (2002).

${ }^{9}$ S. Bandyopadhyay, S. Dasgupta, S. L. Agrawal, and S. K. Mandot, Prog. Rubber Plast. Re. 22, 269 (2006).

${ }^{10}$ N. Roche and L. Perier, Procedia Eng. 66, 705 (2013).

${ }^{11}$ P. Ghosh, R. Stocek, M. Gehde, R. Mukhopadhyay, and R. Krishnakumar, Int. J. Fracture 188, 9 (2014).

${ }^{12}$ J. R. Halladay and F. J. Krakowski, Rubber World 239, 28 (2009).

${ }^{13}$ M. D. Ellul, "Mechanical Fatigue," in Engineering with Rubber: How to Design Rubber Components, A. N. Gent, Ed., Hanser, New York, 1992.

${ }^{14}$ M. El Yaagoubi, D. Juhre, J. Meier, N. Kröger, T. Alshuth, and U. Giese, Int. J. Fatigue 112, 341 (2018).

${ }^{15}$ J. R. Rice, J. Appl. Mech. 35, 379 (1968).

${ }^{16}$ J.-B. Le Cam, B. Huneau, E. Verron, and L. Gornet, Macromolecules 37, 5011 (2004).

${ }^{17}$ J.-B. Le Cam and E. Toussaint, Macromolecules 43, 4708 (2010).

${ }^{18}$ B. Ruellan, J.-B. Le Cam, E. Robin, I. Jeanneau, F. Canévet, G. Mauvoisin, and D. Loison, Eng. Fract. Mech. 201, 353 (2018).

${ }^{19}$ M. Flamm, J. Spreckels, T. Steinweger, and U. Weltin, Int. J. Fatigue 33, 1189 (2011).

${ }^{20}$ Y. L. Tee, M. S. Loo, and A. Andriyana, Int. J. Fatigue 110, 115 (2018).

${ }^{21}$ M. H. Halim, "Truck Tyre Tread Rubber: Compounding and Abrasion Resistance," Ph.D. Thesis, Loughborough University, 1990.

${ }^{22}$ H. J. Kim and G. R. Hamed, RubBer CheM. TECHNOL. 73, 743 (2000).

${ }^{23}$ M. P. Lee and A. Moet, RubBer ChEM. TEChNOL. 66, 304 (1993).

${ }^{24}$ P. Ghosh, R. Mukhopadhyay, R. Kankroli, and R. Stoček, Kautsch. Gummi Kunstst. (2016).

${ }^{25}$ D. H. Abang Ismawi Hassim F. Abraham, J. Summerscales, and P. Brown, Express Polym. Lett. 13, 248 (2019).

${ }^{26}$ K. Reincke, W. Grellmann, and G. Heinrich, RUBBER CHEM. TECHNOL. 77, 662 (2004).

${ }^{27}$ B. Dong, C. Liu, and Y.-P. Wu, Polym. Test. 38, 40 (2014).

${ }^{28}$ ImageJ. https://imagej.nih.gov/ij/.

${ }^{29}$ ABSnake plugins. http://imagejdocu.tudor.lu/doku.php?id=plugin:segmentation:active_contour:start.

${ }^{30}$ E. E. Gdoutos, P. M. Schubel, and I. M. Daniel, Strain 40, 119 (2004).

${ }^{31}$ F. Abraham. "The Influence of Minimum Stress on the Fatigue Life of Non Strain Crystallising Elastomers," Ph.D. Thesis, Coventry University, 2002.

${ }^{32}$ G. R. Hamed, RubBer CHEM. TECHNOL. 67, 529 (1994).

${ }^{33}$ P. B. Lindley, Int. J. Fracture 9, 449 (1973).

${ }^{34}$ J. A. Donovan, Jpn. Rubber Assoc. Mag. 5, 239 (2002).

${ }^{35}$ W. V. Mars and A. Fatemi, RubBer CHEM. TEChNOL. 77, 391 (2004).

${ }^{36}$ T. Zarrin-Ghalami and A. Fatemi, Polym. Eng. Sci. 52, 1795 (2012).

${ }^{37}$ J.-H. Kim and H.-Y. Jeong, Int. J. Fatigue 27, (2005).

${ }^{38}$ M.-J. Wang, Rubber Chem. Technol. 72, (1998).

${ }^{39}$ K. K. Kar and A. K. Bhowmick, J. Appl. Polym. Sci. 65, 1429 (1997).

${ }^{40}$ K. Reincke, W. Grellmann, R. Lach, and G. Heinrich, Macromol. Mater. Eng. 288, 181 (2003).

${ }^{41}$ G. R. Hamed, H. J. Kim, and A. N. Gent, RubBer CHEM. TEChNOL. 69, 807 (1996).

${ }^{42}$ L. Mullins, RuBBER CHEM. TECHNOL. 42, 339 (1969).

${ }^{43}$ V. V. Bolotin, “Mechanics of Fatigue," in Mechanical Engineering Series, Vol. 11, 1st ed., F. A. Kulacki, Ed., CRC Press, Boca Raton, FL, 1999.

${ }^{44}$ M. Wunde and M. Klüppel, RubBer Chem. TeCHNOL. 89, 588 (2016).

${ }^{45}$ J. L. Poisson, V. Orlando, and A. H. Muhr, “The Impact of Strain History on Crack Growth of Rubber,” Tire Technology Expo Conference, Hannover, Germany, February 20-22, 2018. 
${ }^{46}$ B. Dong, C. Liu, L. Zhang, and Y. Wu, RSC Adv. 5, 17140 (2015).

${ }^{47}$ A. R. Payne, J. Polym. Sci. Polym. Symp. 48, (1974).

${ }^{48}$ B. N. J. Persson, O. Albohr, G. Heinrich, and H. Ueba, J. Phys. Condens. Matter 17, R1071 (2005).

${ }^{49}$ G. Weng, H. Yao, A. Chang, K. Fu, Y. Liu, and Z. Chen, RSC Adv. 4, 43942 (2014).

${ }^{50}$ I. Papadopoulos, "Predicting the Fatigue Life of Elastomer Components," Ph.D. Thesis, Queen Mary University of London, 2006.

${ }^{51}$ S. Asare, "Failure of Rubber Components under Fatigue," Ph.D. Thesis, Queen Mary University of London, 2013.

${ }^{52}$ M. Van Der Horst, W. J. McGill, and C. D. Woolard, J. Appl. Polym. Sci. 101, 2423 (2006).

${ }^{53}$ G. J. Lake, RubBER CHEM. TECHNOL. 68, 435 (1995).

${ }^{54}$ P. Kumar, “Investigating the Recycled Rubber Granulate-Virgin Rubber Interface,” Ph.D. Thesis, Queen Mary University of London, 2007.

${ }^{55}$ B. Dong, C. Liu, Y. Lu, and Y. Wu, J. Appl. Polym. Sci. 132, 42075 (2015).

${ }^{56}$ S. Beurrot, B. Huneau, and E. Verron, J. Appl. Polym. Sci. 117, 1260 (2010).

${ }^{57}$ L. Munoz, L. Vanel, O. Sanseau, P. Sotta, D. Long, L. Odoni, and L. Guy, Plast. Rubber Compos. 41, 273 (2012).

${ }^{58}$ H. Sridharan, J. Chanda, P. Ghosh, and R. Mukhopadhyay, Rubber Chem. Technol. XX, XXX (2019).

${ }^{59}$ K. Legorju-Jago and C. Bathias, Int. J. Fatigue 24, 85 (2002).

${ }^{60}$ D. H. Abang Ismawi Hassim F. Abraham, J. Summerscales, and P. Brown, IJMMM 6, 281 (2018).

${ }^{61}$ S. V. Hainsworth, Polym. Test. 26, 60 (2007).

${ }^{62}$ A. N. Gent, M. Razzaghi-Kashani, and G. R. Hamed, RubBER CHEM. TECHNOL. 76, 122 (2003). 